\title{
APPLICATION RESEARCH OF FRP COMPOSITE MATERIAL FOR BUILDING BASED ON TEST EVALUATION
}

\author{
YU Liang ${ }^{1, a}$, REN Xiang-mei ${ }^{2, a}$, LI Mao-de ${ }^{3, b}$ \\ ${ }^{1}$ Gold Mantis School of Architecture, Soochow University, Soochow, Jiangsu, China \\ ${ }^{2}$ Shenzhen Mingqiao Composite Materials Co., Ltd, Shenzhen, Guangdong, China \\ ${ }^{3}$ Tongji Zhejiang College, Architecture Department, Jiaxing, Zhejiang, China \\ ayuliang_163cn@163.com, ${ }^{b}$ limaode@tongji.edu.cn
}

\begin{abstract}
Keywords: FRP, composite material, building, test evaluation
Abstract. Glass fiber reinforced plastics of composite material briefly as FRP, with the properties of high strength, light, corrosion preventive, easy to be Processing convenience and industrialization, which is applied in many fields. Although it has been applied in building, only to small element or unit such as Street kiosks or simple toilet, still not to a whole building, for which the main reason comes from the lack of performance parameter and technical basis of building construction with FRP composite material. In this paper for FRP, through understanding and testing to FRP property and structure performance, the design and application for whole building with FRP is considered, specially by means of testing evolution and factor analysis of building structure so as to develop its characteristic, and based on to satisfy comfort, safety and convenience, to explore a better building structure with FRP and set up new method for FRP and its design process.
\end{abstract}

\section{Introduction}

The basic necessities of life can not be separated with building, Building is a living machine, said by Le Corbusier $^{[1]}$. Purpose of building is to set up an enclosure which is proper for human being to live, at least to be a Shelter, or the better for a comfort and a safe environment. A design is to realize or satisfy these requirements. FRP is a kind of composite materials, fiber reinforced plastics, which using High polymer fiber mixed with synthetic resin matrix and to be solid after Matrix curing ${ }^{[2]}$.FRP with the properties of high strength, light, corrosion preventive and easy to be processing convenience easy industrialization, is widely applied in engineering and civil use, which has the influence on environment condition of living and working. At present, FRP application is not sufficient in the field of building, but it may completely be adapted to the need of Architectural art and Construction of image by its light, high strength, Structure modelling and free design ${ }^{[3]}$.

The classical building is constructed with the materials of clay, brick, wood and some other base materials. The famous Qin brick and Han tile are continues till now, which indicated some excellent skill of Architecture, and symbolized that Chinese Architectural civilization has the long history. Even so, it will consume Large amount of material of natural and Artificial resources and to cause environmental pollution if to construct with the ways of Qin brick and Han tile, and not suitable to Each type of building such as some small tourism building with high corrosion resistance. So here, we take FRP composite material and its construction of building as research item, to bring its excellent property into play and to consider its construction module for building design and process, which will provide Reference basis for building Industrial production in the future.

In the paper, based on the FRP composite material, to consider every link in the building formed from material to construction when to design, through the understanding and testing of material property to think about building design and material usage, specially through the testing to evaluate its application and influence factors, to develop the best nature of materials. At the same, based on the satisfaction of comfort, safe and convenience, to explore a suitable process for small building, and to set up a new way and thought for a combination of FRP materials and building process. 


\section{FRP Application: it has not involved the bone of building material}

FRP material and application

FRP is one kind of composite material, which consists of two different substances, to be mixed or combined together, to overcome self defect when using alone and to develop new advantages when combined. With many kind of types, FRP series display different performances but with high strength, light and better corrosion prevention comparing with steel, brick and wood, saving metals and woods when applied to building. With these prominent advantages, FRP starts its application in building process and is concerned by the engineering community ${ }^{[4]}$. FRP composite materials enhance rigidity and toughness through the way of additive of promotion, solidification and toughness which improves its anti fire and aging. East to form into different shapes, not need regular maintenance, FRP product is made by forming mould from the raw to component or unit, its process mainly by pull and press.

To involve the bone of building material

The application in building of Material composite method is of long standing and well established, accumulated a wealth of experience, such as in Chinese traditional dwelling which plus straw or fiber to increasing hardening performance of wall and with Lime water sometime, so as to be used to construct wall which is not easy to make material fall off. The concrete is one of the best composite materlals which has been applied widely solved the housing needs of the people. Up till now, the more using of FRP is about some kind of building equipment or Construction accessories such as building doors and windows, bath, lighting cover, water supply and drainage fittings, cooling tower and sculpture works and etc. as in Figure 1 and 2. Although FRP citation is applied in many buildings as in Shanghai Yangtze River Estuary which Spherical roof of a revolving restaurant with spherical $45 \mathrm{~m}$, and the decorative pieces of the Oriental Pearl TV Tower roof and inner diameter of $60 \mathrm{~m}^{[4]}$, But the basic used as the construction of the component or ancillary facilities, rare used as building materials. In order to further understand the application status of FRP and glass steel, we take glass steel as the key word to search Chinese HowNet and get less literature about glass steel, some information Time has been a long time. But on the contrary, when to take FRP as the key word to search information about its application, we get a lot and some concerned with building. The same, with Baidu to search application picture, its most usage is as component or unit and which shows that it has not seen the application on Independent whole building. So we conclude that FRP application has not involved the bone of building materials. The word bone means that of structural part of a building frame, which is the most important part in building related with the design key and using security. Conversely to view the present stats of material used in building, it is easy to find that Reinforced concrete dominates the world of building. Author worked and studied in Japan for many years, the deepest impression about FRP application is a box type toilet, which is manufactured as a Unit body and applied widely by means of hoisting or assembling into building from common house to senior hotel, which shows a good integrity, not easy to leakage and better skid resistance, as in Figure 2.

\section{Building application: based on testing evaluation of material performance}

Based the above discussion, here specially for FRP, through holding the function of construction and thermal influence, except to ensuring the safety, it is also to increase the ability to resist temperature and humidity which plays a role to control the building from material through design.

testing evaluation of material performance

From the performance or function of a building material, it is the Basic starting point to show performance or function of material and to perfect its role for a building. For structure function of FRP material, it is to know about its importance of test evaluation and to make a reasonable choice and sort Index. Just for this, we screen the material, structure and thermal factor, take material as the base, to think about test evaluation based on material and to compare other two content, in which test evaluation of building structure is the most important which as the key factor consists of several parameters of FRP material, selected material of basic profiles provided by the manufacturers for test 
evaluation ones is shown as in Figure 3.

A. FRP window

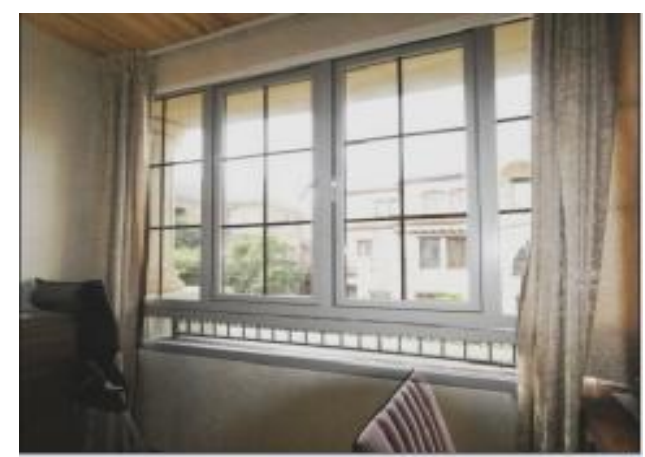

B. Dinner hall chair

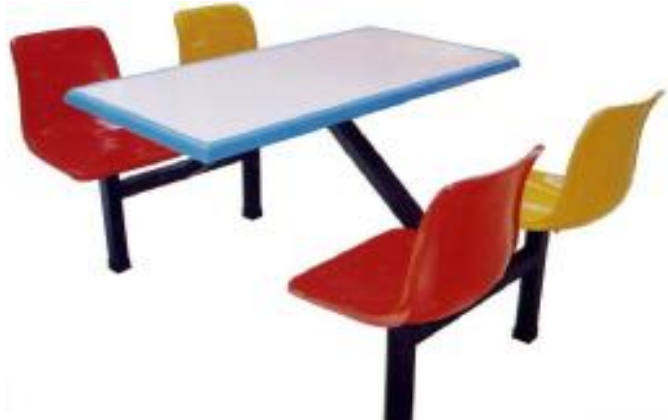

Figure. 1 FRP Material, commonly used unit

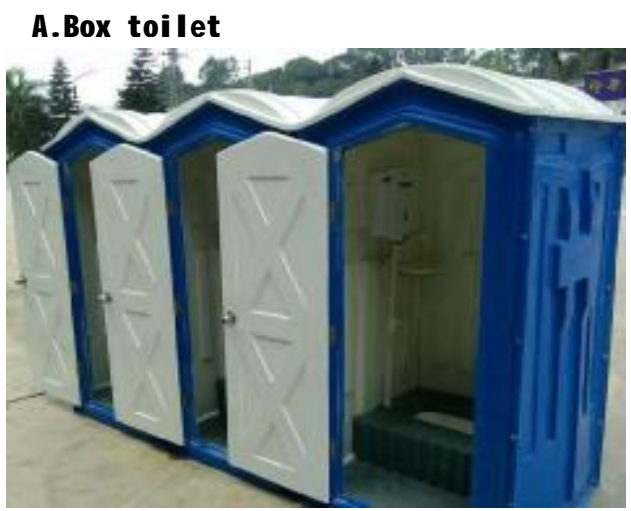

B. Box Bathroom

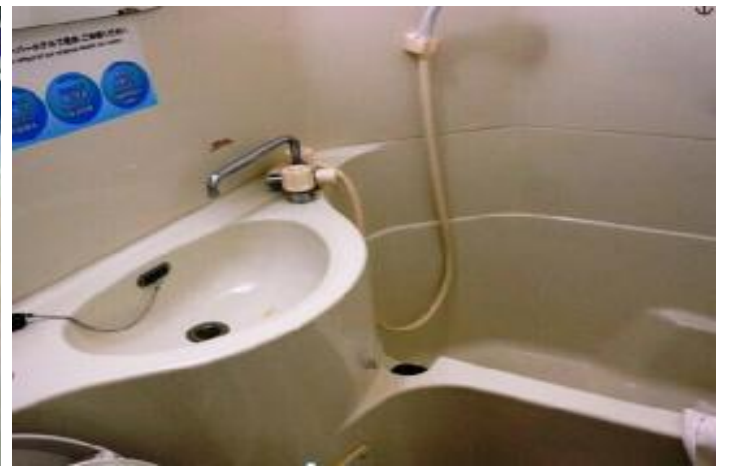

Fiaure. 2 common application in buildina

A. Tubular section

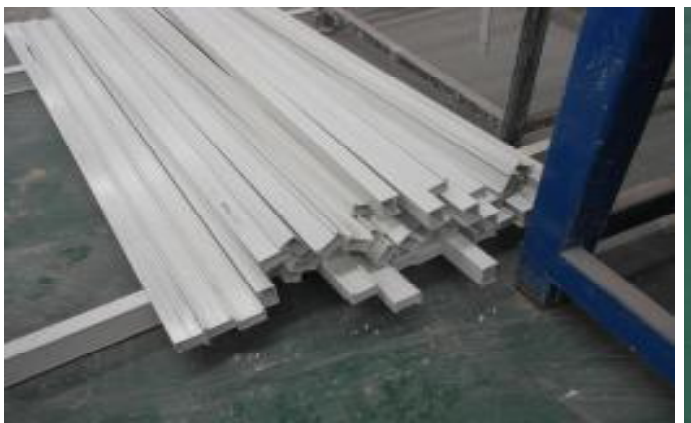

B. Sheet section

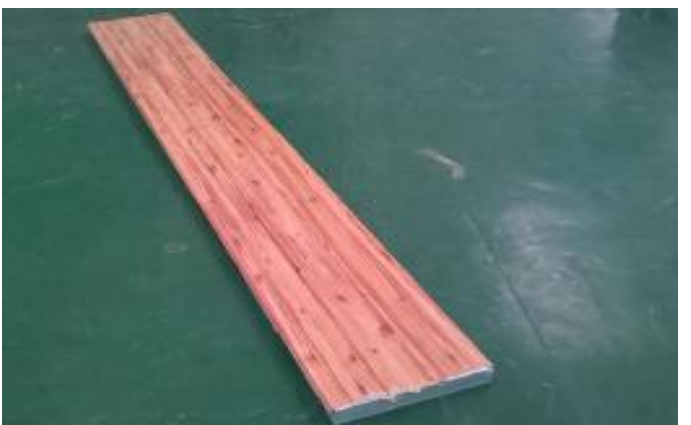

Figure.3 Part of the manufacturer of the material sample

Entailed process and consideration:

a. test of material: to compare with rules of safety and physical and chemical index of building and environment. Mainly it is rely on those data from the manufacture as in Figure.1, to evaluate those of anti fire, anti aging, Physiological health and durability which is the basis to recombination and deployment.

b. test of structure: for permanent safety of building whole, it is necessary to consider Structure stability, Anti-seismic and anti-wind. For lack of FRP structure sample of material mechanics at present, it is mainly used the reference of steel structure and other Architectural design specifications. c. thermal test. Using the Material sample from Manufacturer, Environmental impact test is carried out which mainly to meet the requirements of heat insulation and anti-fire. 
Application of materials for building combination and technology

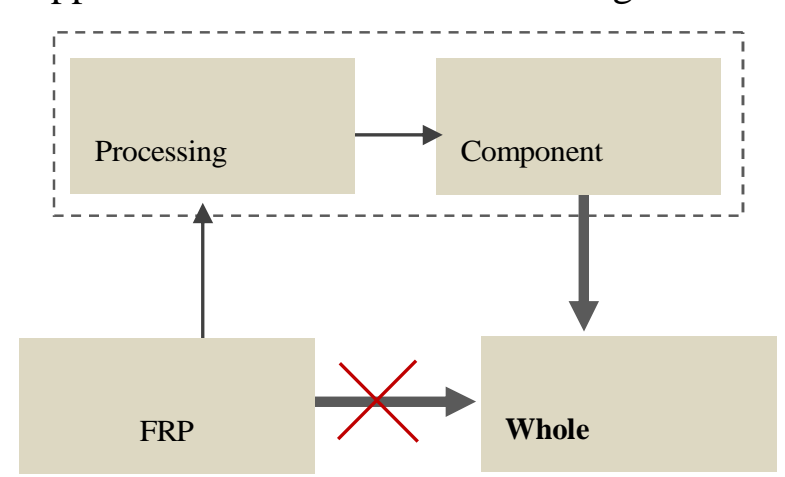

Figure.4 Design concept based on material

Though the performances of different materials differ in thousands of ways, it needs Through reasonable and effective design combination if to form a special structure type, so as to display or show material function and reflect a typical building style. In order to future building to be full of Unique charm of FRP materials, according to material processing and building structure, we divide Building process into three parts as material, component structure and Processing technology,as in Figure.4.

Each links are of Interdependent, mutual connective. It needs to note that, Imagined process of FRP materials using is to manufacture Component in the plant and then at the Construction site to Assembly building. So it needs to form a reasonable and perfect Structure method which is construction means and related with building structure system and Structure generation method. Processing technology is about the process of component of FRP material from base material to building, which production in plant, assemble in

Table.1 Based on performance enhance of FRP Building application

\begin{tabular}{|c|c|c|c|c|c|}
\hline NO & Perspective & Effect & Purpose & Test evaluation & Reinforcement means \\
\hline 1 & Material & $\begin{array}{l}\text { Effect of } \\
\text { forming, } \\
\text { building, } \\
\text { material base }\end{array}$ & $\begin{array}{l}\text { Performance confirmation, } \\
\text { The connection with other } \\
\text { concerns, Maximize the } \\
\text { performance of the material }\end{array}$ & $\begin{array}{c}\text { fiber property, } \\
\text { Bonding filling material, } \\
\text { Mechanical and thermal }\end{array}$ & $\begin{array}{l}\text { Add other materials, fiber } \\
\text { selection, Bonding material } \\
\text { modification, Adaptation } \\
\text { materials and recombination }\end{array}$ \\
\hline 2 & structure & $\begin{array}{c}\text { Frame } \\
\text { function of } \\
\text { architecture } \\
\text { and } \\
\text { component } \\
\end{array}$ & $\begin{array}{l}\text { Suitable structural system } \\
\text { Meet the safety requirements } \\
\text { of the earthquake, wind and } \\
\text { fire and so on, Ensure } \\
\text { stability }\end{array}$ & $\begin{array}{l}\text { Strength and installation } \\
\text { characteristics of } \\
\text { Combination of different } \\
\text { structural types }\end{array}$ & $\begin{array}{c}\text { Load bearing system } \\
\text { Structural connection and } \\
\text { fixation for FRP } \\
\text { Coordination, Easy } \\
\text { assembly }\end{array}$ \\
\hline 3 & thermal & $\begin{array}{c}\text { Living } \\
\text { environment }\end{array}$ & $\begin{array}{l}\text { Consider region climate, } \\
\text { To set Scale factor of Heat } \\
\text { preservation and heat } \\
\text { insulation }\end{array}$ & $\begin{array}{l}\text { Connection precaution of } \\
\text { Wall panels, roof, } \\
\text { structure, to modify } \\
\text { structure design of Node } \\
\text { and surface material }\end{array}$ & $\begin{array}{l}\text { Energy consumption } \\
\text { analysis and saving } \\
\text { optimization, thermal } \\
\text { insulation and heat } \\
\text { prevention of component, } \\
\text { Adjustment design, Form a } \\
\text { reasonable combination }\end{array}$ \\
\hline 4 & $\begin{array}{c}\text { Scale } \\
\text { production }\end{array}$ & $\begin{array}{c}\text { Modular, } \\
\text { standardized }\end{array}$ & $\begin{array}{l}\text { Suitable for industrial } \\
\text { production, Consider the } \\
\text { convenience of construction } \\
\text { work, do best for the } \\
\text { standardization of } \\
\text { components and general }\end{array}$ & $\begin{array}{l}\text { Wall panels, roof, floor, } \\
\text { Decorative and special } \\
\text { components, Type } \\
\text { characteristics and } \\
\text { distinction }\end{array}$ & $\begin{array}{l}\text { According to Modular, } \\
\text { standardized } \\
\text { structure,Determine } \\
\text { component size } \\
\text { specifications }\end{array}$ \\
\hline
\end{tabular}

Construction site, Production mode and equipment capability will influence the effect of Building, and Technological level will determine Accuracy of building. Ii is the Process enrichment and induction for above links.

No matter how component or processing links, their mutual bases are material, through to display performance to make three links to realize Seamless connection and through, and Design integration to let three parts to form a reasonable structure system, so as to meet demands of Architectural design diversity.

Testing evaluation of structure and thermal

Because of the bigger difference with other classical structure for FRP material and its component and shape and its special property under different mechanical action for its special fiber structure, so in the 
design process to consider building structure, its mechanical performance must be tested and give a evaluation including mechanical strength evaluation of its unit and component.

A lot of experience shows that, Due to geographical position difference, The thermal effects of the building structure will vary greatly. When material is heated or cold by sun or environmental action, if mechanical strength can not keep enough performance, building structure will appear dangerous. If under heat or cold, Heat transfer exceeds the extent of building limit, the thermal environment in the building will be degrade and to jeopardize the function of comfort and effect of building. So for different materials and their structure, it is used for single unit a direct mechanical test and model test for component, which to give out Comprehensive evaluation and to provide important Reference data for design.

\section{Conclusion}

To display performance of FRP materials to consider building design and assemble, it is indicated the mutual relationship among materials, component and processing, emphasized that, Modeling effect from the material ,Group structure of whole building and Structure rationality for safety, through a process of structure test and thermal test, to provide technical base for building product of FRP materials. At same time, it shows that the necessity of precipitation and integration of Technology. Because lack of reference building sample, so it left many problems to be solved. And so on, it is demanded for designer both to know about Professional technology and to Expand knowledge in other areas and with a Effective integration of Technology. No matter how building with FRP has started, although there still exists many problems to be explored and solved, all of these are valuable to be researched or developed. Just because of this, it can be expected that the Popularization and application of FRP materials and its application will become more and more common.

\section{Reference}

[1] Le Corbusier. Vers Une Architecture [M]. Shaanxi Normal University press. 2004,1. Translation by Zhihua Chen.

[2] Wu Lili, Yu Dachuan. Application and outlook of FRP material in the process of Structure strengthening. Architecture Technology. 2014,45(12):1099-1101

[3] He Yusheng. Architectural art and design of fiber reinforced plastics[J]. Fiber reinforced plastics. 1983(12):29-34.

[4] Ye Yulie, Feng Peng. Application and development of FRP in the engineering construction. Journal of Civil Engineering. 2006, 39(3): 24-36

[5] Jiang Hansheng, Jin Yihong. Application of FRP in the field of building. Fiber reinforced plastics /composite materials. 1999(3):33-34.

[6] Wei Rong. The control of design process of FRP product[J]. Fiber reinforced plastics /composite materials. 1998,06

[7] He Shuiqing. Effect of energy saving of building of FRP doors and windows. Energy saving of architecture[J].2008.2.34-38

[8] Zeng Xufang, Ji Yuanjing,Chen Wen etc.. Development of Heat preservation material of EPS of Composite fiber modification[C]. 2011-Association Annual Meeting collection of China heat insulation and energy saving

[9] Zhan Songlin,Han Qingmiao,LiuChanbing. Analysis of Market demand factors based on selection theory of building energy saving[J]. Journal of Beijing Jiaotong University (SOCIAL SCIENCE EDITION. 2009, 01. 
